\title{
Is there a difference in observed bone mineral density at diagnosis of overt or subclinical thyrotoxicosis?
}

\author{
McHugh, C.M., Hession, P.
}

Department of Endocrinology, Sligo Regional Hospital, Sligo, Ireland

\section{Introduction}

Both overt and subclinical thyrotoxicosis is associated with loss of bone mineral density and osteoporosis 1,2 The occurrence in both disorders has led to the belief that it is related the low TSH levels. TSH intermittent administration has been shown to improve bone mineral density in rats ${ }^{3}$.

\section{Aims}

The aim of this study is to determine any difference between bone mineral density in those presenting with overt or subclinical thyrotoxicosis.

\section{Methods}

This study is retrospective observational study of bone mineral density in all individuals presenting to a secondary care facility in Ireland for managemen of thyrotoxicosis from February 2008 to July 2013. Bone mineral density was assessed by bone densiometry with estimation of $T$ in those $\geq 50$ years of age and $Z$ scores in those $<50$ years of age.

Definition:

Overt thyrotoxicosis was defined as free T4 $>19.0$ $\mathrm{pmol} / \mathrm{L}$ TSH $<0.35 \mathrm{ulU} / \mathrm{ml}$,

subclinical thyrotoxicosis was defined as freeT4 $<19.0 \mathrm{pmol} / \mathrm{L}, \mathrm{TSH}<35 \mathrm{ulU} / \mathrm{ml}$ at diagnosis.

\section{Inclusion and exclusion} criteria

\section{Inclusion criteria}

- TSH $<0.35 \mathrm{ulU} / \mathrm{ml}$ within 1 year of the DEXA scan date.

\section{Exclusion criteria}

- Osteoporosis or osteopenia on DEXA prior to the first low TSH.

- History of thyroid cancer with pharmacologically induced TSH suppression

- Hyperparathyroidism or other illness that may induce osteoporosis

- Pituitary pathology requiring steroid supplementation

- Antithyroid medication for 2 years or more prior to scan

\section{Results}

91 people were included: 64 women, 27 men.

49 had overt thyrotoxicosis at diagnosis $(\mathrm{n}=15$ aged 20 50 years, $n=34$ aged $>50$ years), 40 had subclinical thyrotoxicosis (5 aged 20-50years, 35 aged $>50$ years).

Number of people with overt or subclinica thyrotoxicosis in study

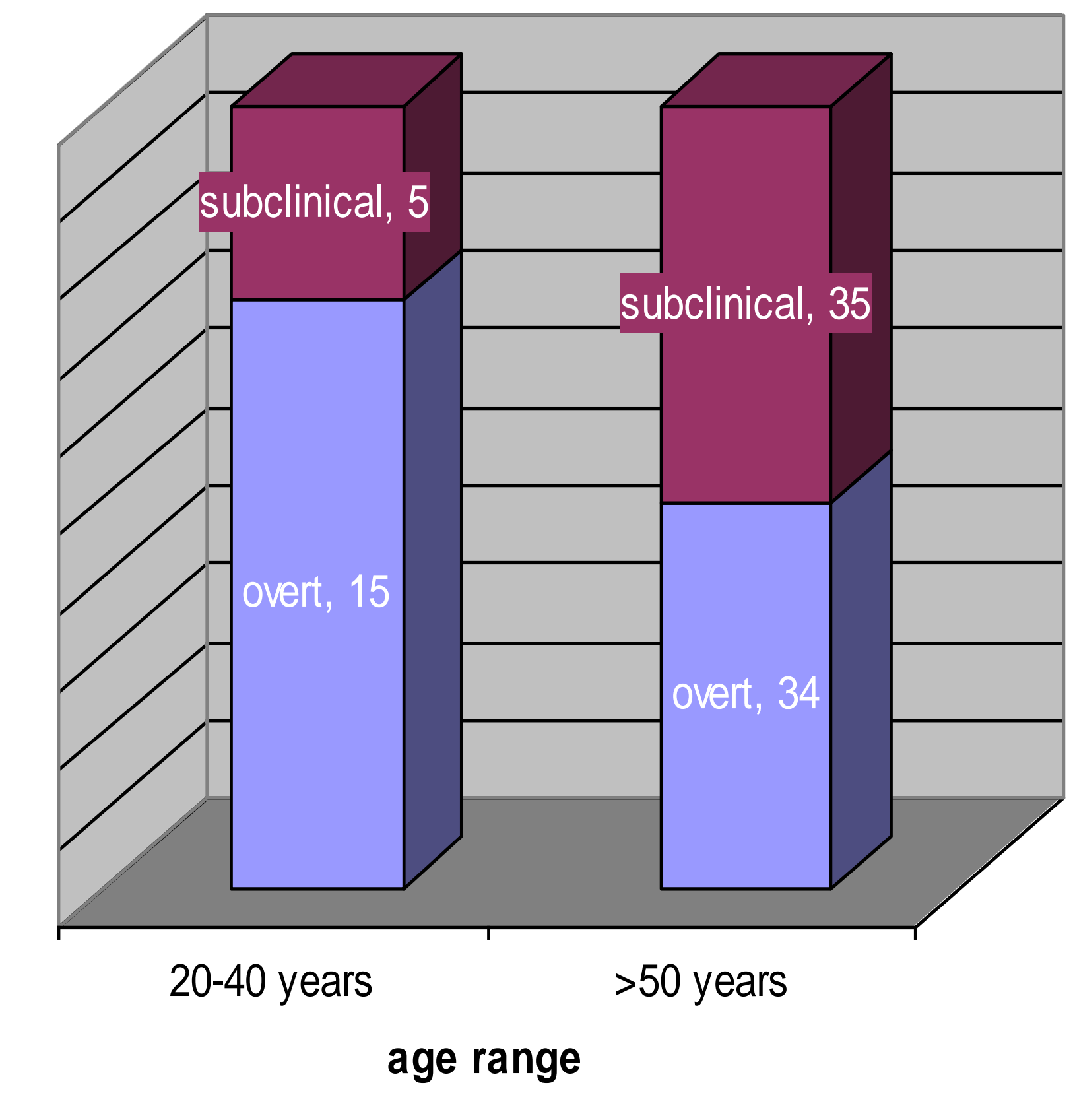

Figure 1 Number of people in the study with overt and subclinical hyperthyroidism

\section{Age range}

The median age was 43 years (overt), 42 years (subclinical) aged $20-50$ years, 58.5 (overt), 70 years (subclinical) in the $>50$ years group.

\section{TSH}

In those aged 20 to 40 years the mean TSH at diagnosis $(\mathrm{n}=20)$ was $0.03 \pm 0.02 \mathrm{U} / \mathrm{ml}$, fT4 $27.17 \pm 2.5 \mathrm{pmol} / \mathrm{L}$

In the $>50$ years age $(n=69)$ mean TSH was $0.16 \pm 0.04 \mathrm{pmol} / \mathrm{L}, \mathrm{fT} 421.46 \pm 1.34 \mathrm{pmol} / \mathrm{L}$.

\section{BMD}

There was no difference in BMD in overt or thyrotoxic patients in any of the age ranges.

Age 20 to 50 years $L 1 L 4 p=0.3$, Left neck of femur $p=0.6$, right neck $p=0.5$. Aged 50 years 20 to 50 years $L 1 L 4 p=0.4$, Left neck of femur $p=0.4$, right neck $p=0.3$, radius $p=0.2$.

\section{T,Z scores}

In the 20-50years age group 4 had a $Z$ score $<-2.5,2$ in $1 L 4$ and 2 femoral neck (all subclinical). 12 had $Z$ scores between -2.5 and -1.0 (2 in L1L4 (2 overt) and 10 femoral neck ( 7 overt, 3 subclinical).

Aged $>50$ years 30 had T scores $<-2.5$ (L1L4(10 overt, 6 subclinical) 12 femoral neck ( 6 overt, 6 subclinical) 2 radius (subclinical), 84 had T scores -1.0 to -2.5 (L1L4 (7 overt, 12 subclinical), 64 femoral neck (35 overt, 29 subclinical) and 1 radius (subclinical).

\begin{tabular}{|c|c|c|c|c|}
\hline \multirow[t]{2}{*}{ age 20to } & 50 years & L1L4 & \begin{tabular}{|l|} 
right \\
femur \\
neck
\end{tabular} & $\begin{array}{l}\text { left femur } \\
\text { neck }\end{array}$ \\
\hline & & $\mathbf{n}$ & & \\
\hline ert & $Z<-2.5$ & 0 & 0 & 0 \\
\hline & $Z-1.0$ to -2.4 & 2 & 3 & 4 \\
\hline & $Z>0.9$ & 13 & 12 & 11 \\
\hline $\begin{array}{l}\text { Sub } \\
\text { clinical }\end{array}$ & $Z<-2.5$ & 2 & 1 & 1 \\
\hline & $Z-1.0$ to -2.4 & 0 & 1 & 2 \\
\hline & $Z>0.9$ & 3 & 3 & 2 \\
\hline
\end{tabular}

Table 1. Z scores for the overt and subclinical thyrotoxicosis groups aged 20 to 50 years

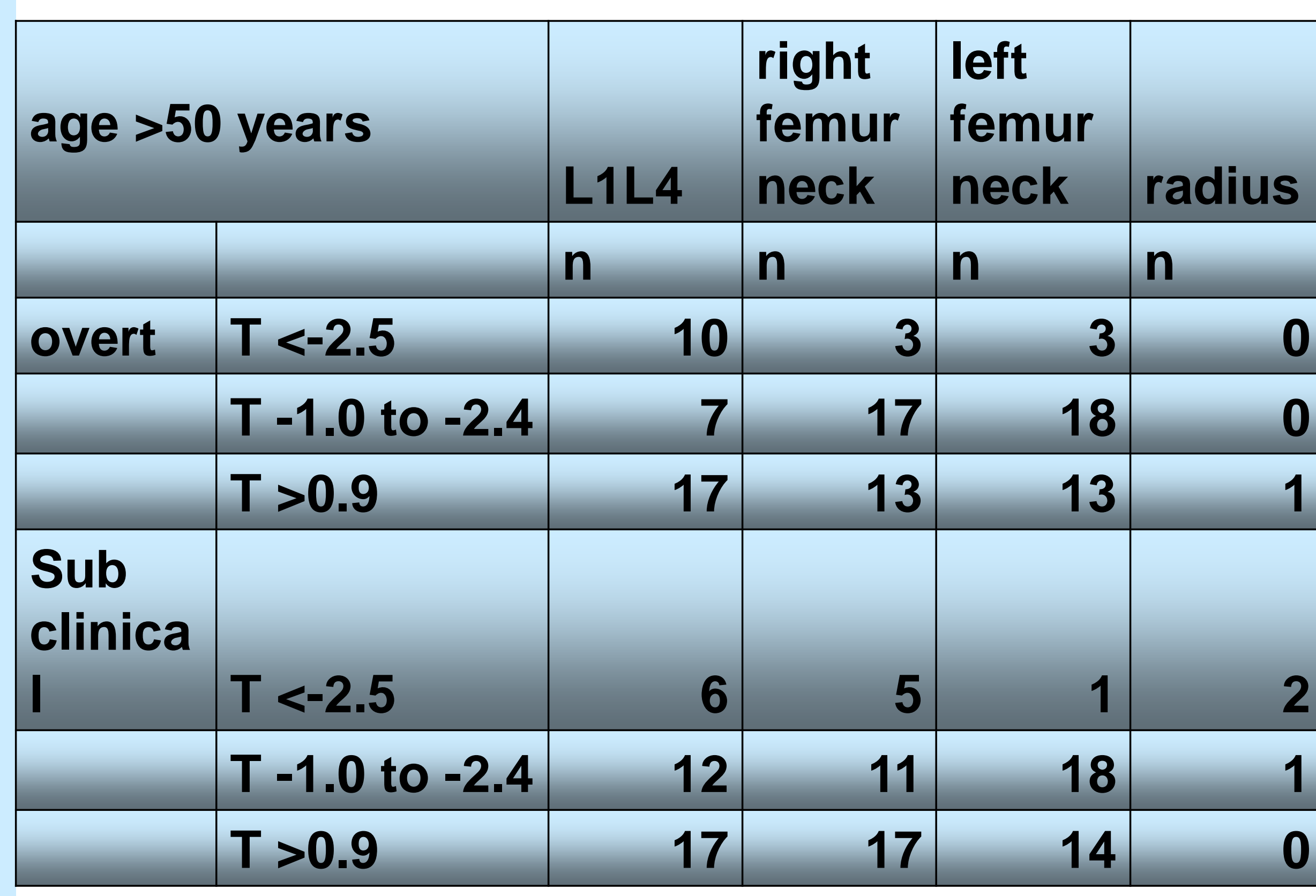

Table 2. T scores for the overt and sutclinical thyrotoxicosis groups aged $>50$ years.

\section{Conclusion}

There is no difference in $Z$ score and T score between those who presented with overt thyrotoxicosis and those with subclinical thyrotoxicosis. There were a number with $Z$ scores 2.5 to -1.0 which merit rescanning but overall the prevalence of lower T scores in those aged $>50$ years presenting with thyrotoxicosis was high (30 of the 50 patients) and this was their first DEXA. This study highlights the importance of DEXA scanning in this age group.

\section{References}

1. Sachan A, Harinarayan $C$, et al. Bone disease in thyrotoxicosis. Indian J Med Res. 2012;135:277-86. 2. Sendak RA, Sampath TK, et al. Review Newly reported roles of thyroid-stimulating hormone and folliclestimulating hormone in bone remodelling. Int Orthop. 2007 Dec; 31(6):753-7.

3. Sampath TK, Simic $P$, et al. Thyroid-Stimulating Hormone Restores Bone Volume, Microarchitecture, and Strength in Aged Ovariectomized Rats. J Bone Miner Res. 2007;22:849-59. 